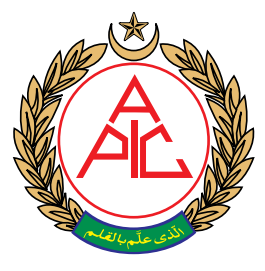

${ }^{1}$ Consultant Anesthesiologist, Kaul Associates (Pvt) Ltd. Lahore (Pakistan).

${ }^{2}$ Consultant Anesthesiologist, Shaukat Khanum Memorial Cancer Hospital \& Research Centre, Lahore (Pakistan).

Correspondence: $\mathrm{Dr}$ Muhammad Adeel Bashir (adeel47a@gmail.com)

Received: 18 February 2020;

Reviewed \& Accepted: 24

February 2020

\section{Novel coronavirus (COVID-19): Its implications for anesthesia}

\author{
Muhammad Adeel Bashir ${ }^{1}$, Romana Shahida Durrani ${ }^{2}$
}

\begin{abstract}
Once again in the same decade, global health delivery systems are facing with the daunting challenge of another variant of Coronavirus (COVID-19). Over the last 20 years at least six different variants of coronavirus have emerged. Infections caused by these viruses mainly cause life threatening respiratory implications. The recent outbreak of a novel Coronavirus in Wuhan, China has been labelled as public health emergency of international concern (PHEIC). Previous experiences of Coronavirus outbreaks have shown that health care workers are at a high risk of acquiring this infection. Anesthesiologists, are particularly vulnerable due to their frequent exposure to infected respiratory secretions. Therefore, to minimize the transmission of nCoV-2019 infection, proper infection control measures like correct workplace practices, appropriate usage of personal protective equipment, airborne and droplet precautions are mandatory while managing a suspected case of infected patient.
\end{abstract}

Key words: Novel coronavirus; COVID-19; Coronavirus, Implications

Citation: Bashir MA, Durrani RS. Novel coronavirus (COVID-19): Its implications for anesthesia. Anaesth pain intensive care 2020;24(1):1-3

DOI: https://doi.org/10.35975/apic.v24i1.1214
After a recent out-break of novel Coronavirus (COVID-19) infection in the central Chinese city of Wuhan, cases have also been reported from other parts of China, as well as from the countries surrounding the Chinese borders. Pakistan, which has close economic ties with China, is particularly at risk of transmission of such an infection. ${ }^{1}$ Healthcare workers, especially anesthesiologists, are vulnerable as they are routinely involved in performing procedures that expose them to high concentrations of infected material. Therefore, adequate knowledge of the disease epidemiology and preventive measures is imperative for all healthcare workers. ${ }^{2}$

Coronavirus is derived from the Latin word corona, which means a crown. When viewed under an electron microscope, multiple spikes arising from the membrane covering of the viral particle, gives a resemblance of a crown and hence, the name 'coronavirus'. It is an enveloped single stranded RNA virus which has phylogenetically been classified into four genera; Alpha, Beta, Gamma and Delta coronaviruses. Mammals are mainly affected by the alpha and the beta variants, whereas gamma and delta coronaviruses mainly affect birds. ${ }^{3,4}$
Coronaviruses can cause infections of the central nervous system, respiratory tract, gastrointestinal and renal systems. In humans, however, the main manifestations of this infection appears to involve the respiratory and the gastrointestinal tracts. At least six species of corona viruses are known to cause infections in the human population. The severity of these illnesses ranges from common cold like symptoms to life threatening severe pneumonia and renal implications. ${ }^{4,5}$

In the last twenty years three deadly outbreaks of coronavirus infections have devastated the human race. The first outbreak of severe acute respiratory syndrome (SARS) occurred in China in 2002. This infection, with a high incidence of transmission, resulted in the mortality rate of $10 \%$. In 2012, a second outbreak of coronavirus, in the form of Middle East Respiratory Syndrome (MERS), occurred in the Middle East. This species of coronavirus is still prevalent in the Arabian Peninsula. Even though, its human to human transmission is low, it has high mortality rate of $36 \%$. The latest addition to the species of coronaviruses made its appearance in December 2019 in Wuhan China. This virus has been designated as COVID-19. The exact information 


\section{novel coronavirus and anesthesia}

regarding the origin and mode of transmission remains to be ascertained, however, several cases of COVID-19 infection have been reported by various countries. ${ }^{1,5,6}$

The occurrence of three epidemics in the last twenty years has raised global health concerns, including concerns regarding the health and wellbeing of the healthcare workers. Previous experiences with SARS associated coronavirus (SARS- $\mathrm{CoV}$ ) and Middle East respiratory coronavirus (MERS-CoV) has shown that these infections can be transmitted by droplets as well as close contact with infected patients and biological material. Such infections have been reported, in healthcare workers despite the use of droplet and contact precautions. ${ }^{6,7,8}$

Anesthesiologists, are particularly vulnerable as they are routinely exposed to respiratory secretions during airway management. Procedures such as bag mask ventilation and endotracheal intubation during elective airway management or at the time of cardiopulmonary resuscitation, have known to transmit infections to the individuals involved in these procedures. Non-invasive positive pressure ventilation and high frequency jet ventilation are examples of other common techniques employed by anesthesiologists that can generate large quantities of aerosolized viral load. ${ }^{7.9}$

Drawing on experience from previous zoonotic coronavirus infections, healthcare authorities have devised recommendations for managing patients with suspected or confirmed coronavirus infection. However, most of these guidelines do not specifically give guidance regarding management of these patients in the operating room. ${ }^{9}$

Recently, American Society of Anesthesiologists have published recommendations for the management of COVID-19 suspected or infected patients in the perioperative period. The recommendations state: ${ }^{10}$

Health care workers should use N95 or higher respiratory masks. Eyes should be protected by using goggles or face shields.

Personal protective equipment (PPE) should include gowns and gloves.
Regular hand hygiene should be implemented.

All elective procedures should be deferred until active infection has been ruled out.

Minimize contact with other patients and health care staff.

During the transport of such patients, fresh PPE should be used so as to reduce the spread of fomites to other parts of the facility.

During regional techniques, patient should continue using a surgical face mask in theatre.

High efficiency particulate filters (HEPA) should be used between circuits and airway devices used to maintain the airway.

All gases should be scavenged and not allowed in to the theatre environment.

Closed suctioning systems should be used for airway suctioning.

Post procedure, operating room should be left unused so that $99.9 \%$ of air turnover has occurred. This would mean a duration of 28 mins for systems that achieve 15 exchanges of air per hour.

Equipment such as ultrasound should be draped to prevent unnecessary contamination.

All surfaces should be cleaned with a recommended disinfectant post procedure.

As the COVID-19 infection has the potential to pose serious risk to health which can result in death and high rate of transmissibility, Centre of Disease Control and Protection (CDC) recommends that health care staff should be on the lookout for any suspected cases and ensure strict compliance to the use of precautionary measures laid out in the guidelines. $^{2}$

Conflict of interest: None declared by the authors

Authors' contribution:

$M A B$ - Conceived the idea, main author of the manuscript

RSD - Edited and corrected the manuscript 


\section{REFERENCES}

1. Munster VJ, Koopmans $\mathrm{M}$, van Doremalen N, van Riel D, de Wit E. A novel coronavirus emerging in China-key questions for impact assessment. N Engl J Med. 2020;382(8):692-4. [PubMed] DOl: 10.1056/NEJMp2000929

2. Coronavirus disease 2019 (COVID-19). CDC. [Free full text]

3. Cui J, Li F, Shi ZL. Origin and evolution of pathogenic coronaviruses. Nat Rev Microbiol. 2019;17(3):181-92. [PubMed] D0I: 10.1038/s41579-0180118-9

4. Su S, Wong G, Shi W, Liu J, Lai AC, Zhou J, et al. Epidemiology, genetic recombination, and pathogenesis of coronaviruses. Trends Microbiol.
2016;24(6):490-502. [PubMed] DOI: 10.1016/i.tim.2016.03.003

5. Masters PS. Coronavirus genomic RNA packaging. Virology. 2019;537:198-207. [PubMed] DOl: 10.1016/i.virol.2019.08.031

6. Phan LT, Nguyen TV, Luong QC, Nguyen TV, Nguyen $H T$, Le $H Q$, et al. Importation and human-tohuman transmission of a novel coronavirus in Vietnam. N Engl J Med. 2020;382(9):872-4. [PubMed] DOI: 10.1056/NEJMc2001272

7. Christian MD, Loutfy M, McDonald LC, Martinez KF, Ofner M, Wong T, et al. Possible SARS coronavirus transmission during cardiopulmonary resuscitation. Emerg Infect Dis.
2004;10(2):287-93. [PubMed] DOI: 10.3201/eid1002.030700

8. Memish ZA, Zumla Al, Assiri A. Middle East respiratory syndrome coronavirus infections in health care workers. $N$ Engl $J$ Med. 2013;369(9):884-6. [PubMed] DOI: 10.1056/NEJMc1308698

9. Peng PW, Wong DT, Bevan D, Gardam M. Infection control and anesthesia: lessons learned from the Toronto SARS outbreak. Can J Anaesth. 2003;50(10):989-97. [PubMed] DOI: 10.1007/BF03018361

10. Coronavirus (2019-nCoV), information for health care professionals. Committee on Occupational Health. [Free full text] 